\title{
Advancing human health, safety, and well-being with healthy buildings
}

\author{
Sara O. Marberry ${ }^{1}$, Robin Guenther ${ }^{2,3}$, Leonard L. Berry ${ }^{4,5}$ \\ ${ }^{1}$ Principal Consultant, Sara Marberry, LLC, Evanston, IL, USA; ${ }^{2}$ Principal, Perkins \& Will, Senior Advisor, New York, NY, USA; ${ }^{3}$ Health Care \\ Without Harm, Reston, VA, USA; ${ }^{4}$ Department of Marketing, Mays Business School, Texas A\&M University, College Station, TX, USA; ${ }^{5}$ Senior \\ Fellow, Institute for Healthcare Improvement, Boston, MA, USA \\ Contributions: (I) Conception and design: LL Berry, SO Marberry; (II) Administrative support: LL Berry; (III) Provision of study materials or patients: \\ None; (IV) Collection and assembly of data: All authors; (V) Data analysis and interpretation: None; (VI) Manuscript writing: All authors; (VII) Final \\ approval of manuscript: All authors. \\ Correspondence to: Leonard L. Berry. Department of Marketing, Mays Business School, Texas A\&M University, College Station, TX, USA. \\ Email: berryle@tamu.edu.
}

\begin{abstract}
More than a decade ago, the Healthier Hospitals Initiative challenged health systems to improve sustainability and safety in the healthcare sector. Since then, the design and creation of healthy healthcare buildings has become a key component of improving individual and population health, guided by the idea that built environments should facilitate, not impede, progress toward healthful lifestyles and better health outcomes. This movement is grounded in research to inform the evidence-based design process, the science and aesthetics of green and well buildings, metrics on health outcomes for patients and staff, and longterm financial benefits for healthcare organizations. This article is an informed synthesis and analysis of best practices that represent the key features of healthy buildings; discusses research-based building-design interventions, protocols, and policies that promote the creation of healthy buildings; outlines pertinent building-certification programs and standards; identifies the measurable benefits of healthy buildings for patients, staff, financial stakeholders, and communities; and recommends specific actions that hospital and health system leaders can take to make healthy buildings a reality benefiting all stakeholders Examples of institutions that have been successful in this effort are offered as possible models and sources of inspiration for organizations that aim to make their built environments healthier.
\end{abstract}

Keywords: Healthy buildings; evidence-based design; environmental sustainability; hospital design

Received: 27 August 2021; Accepted: 26 November 2021; Published: 25 June 2022.

doi: 10.21037/jhmhp-21-63

View this article at: https://dx.doi.org/10.21037/jhmhp-21-63

In 2010, a coalition of major U.S. health systems formed the Healthier Hospitals Initiative. Their aim was to improve sustainability and safety across the healthcare sector. Today, thousands of other health systems and hospitals have joined the effort by implementing sustainable operating practices, greening their supply chain, reducing their waste footprint, increasing their resiliency in the face of weather events driven by climate change, and pursuing sustainable building design and decarbonization. Despite this progress, many health systems lag in combining environmentally sustainable building design with what's known as "well building design" to create buildings that harm neither person or the planet. Hospitals and health systems can and must become better stewards of human health inside their buildings—and outside of them.

This article briefly outlines the history and evolution of what are often called "healthy buildings," as well as the research-informed building-design interventions and operational protocols and policies that advance human health and well-being. A synthesis of best practices, it 
also more fully examines the benefits of healthy buildings for patients, staff, and the broader community; discusses the return on investment (ROI) of healthy buildings; and identifies concrete actions that hospital and health system leaders can take to encourage and guide the creation of healthy buildings.

\section{Healthy buildings and why they matter}

A healthy building is intentionally designed and operated to support the health, safety, and well-being of the people who use it, as well as the health of the planet. Healthcare facilities have long incorporated some features of healthy buildings, such as improved indoor air quality, but the COVID-19 pandemic has further bolstered awareness of how the design of a building and its surroundings helps to keep people healthy and safe. Health system leaders are now revisiting infection-control strategies and exploring new waiting room design concepts to promote physical distancing, ultraviolet-light disinfecting systems to kill germs, and touchless technologies for doors, handles, and light switches to reduce contact with surfaces. Outdoor spaces that connect humans to the natural world, reducing stress and improving well-being, also have received renewed attention for their relative safety when used as break areas for staff or respite settings for patients and families.

Physical environments unquestionably affect human health (1). The stakes are especially high in healthcare settings, where patients' medical conditions make them vulnerable and their stress and anxiety levels are elevated. Nurses, physicians, and other clinicians also experience daily emotional and physical stress due to the inherent nature of the work (2).

The health of buildings has the potential to improve measurable outcomes. These include the health of patients and staff; staff satisfaction and productivity; and community health, engagement, and inclusion. In addition, building design and operation influence population health by affecting levels of pollution and other environmental factors, such as carbon footprint, related to climate change (3). Overall, about one-fourth of all global healthcare greenhouse gas emissions are generated by the U.S. healthcare system, which is more than any other nation's healthcare system (4).

\section{A brief bistory}

The concept of a healthy building in healthcare goes as far back as the Asclepius Healing Centers in ancient Greece, which were built to treat the body, soul, and mind. Historians believe that site locations for these healing centers were selected for their natural beauty, spectacular views, and thermal springs (5). Buildings and structures for patients to use for recreation and exercise, such as theaters, stadiums, and gyms, also were part of the healing centers.

Centuries later, after seeing the effect of the deplorable conditions of the British hospital barracks on wounded soldiers during the Crimean War in the 1850s, Florence Nightingale became a leading advocate for better healthcare buildings. She wrote, "It may seem a strange principle to enunciate as the very first requirement in a hospital is that it should do the sick no harm." (6). Nightingale believed that patients breathing their own air would become sick or remain sick-that access to fresh air was crucial. She felt that noisy environments harmed patients and that aesthetic changes in the facility were essential to healing. Rotating paintings or engravings and bringing in flowers and plants for patients to experience were two of Nightingale's solutions for positive distractions (7).

The evidence-based design movement that originated in the U.S. in the 1990s was the first to assert the essential role of research into the link between the physical environment and health outcomes. Analogous to evidencebased medicine-whereby clinicians use the best available evidence, plus their own experience and insight, to make medical decisions-evidence-based design is a process whereby architects and designers make well-researched decisions about the built environment.

\section{Evidence-based design}

Table 1 outlines the eight-step evidence-based design process (8). Many studies have shown that decisions about architecture, interior design, and mechanical systems can help to reduce rates of infection, respiratory-related illness, medication errors, injuries from falling or lifting, stress, and anxiety (9-13). The Center for Health Design's Research Repository currently has more than 4,600 research citations on design-related outcomes, features, and processes that help to guide decision-making (14).

Because environmental hazards-including air pollution, toxic chemicals, and carbon emissions-are increasingly linked to the rise in chronic health conditions globally $(15,16)$, a movement has emerged in healthcare to design and operate facilities, as well as make purchasing decisions, that do less harm to the environment. The recognition of the enormous 
carbon footprint of the U.S. healthcare sector makes a strong case for rapid decarbonization of the sector (4).

\section{“Green" and "well" buildings}

The green building design movement began in the 1970 s after increases in oil prices created a desire to improve energy efficiency in all building types. As a result, buildings were significantly "tightened" to reduce air infiltration, a trend that contributed to increases in both "sick building syndrome" and "building-related illness", which gained notoriety in the 1980s and 1990s (17). Hence, environmental sustainability broadened to include strategies for creating healthy indoor environments.

At the same time, biophilia-the concept of increasing

Table 1 The eight-step evidence-based design process

(I) Define evidence-based goals and objectives

(III) Find sources for relevant evidence

(III) Critically interpret relevant evidence

(IV) Create and innovate evidence-based design concepts

(V) Develop a hypothesis

(VI) Collect baseline performance measures

(VII) Monitor implementation of design and construction

(VIII) Measure post-occupancy performance results

Adapted from Ref. (8). occupant connectivity to the natural world using direct and indirect nature-entered design discourse. Popularized by biologists E.O. Wilson and environmental psychologist Judith Heerwagen, a growing body of research has supported the integration of daylight and views, access to the outdoors, and the integration of place-based natural and cultural references in the built environment as key components of a health-promoting building (18-21). The growing focus on how a building affects its occupants spurred the "well building" movement in the mid-2000s. Unlike green design, which focuses on how buildings affect both occupants and the environment (Figure 1), well building design primarily focuses just on the effects on occupants. Both design efforts are essential to creating healthy buildings, and specific certification programs and planning tools address each: The U.S. Green Building Council's Leadership in Energy and Environmental Design (LEED) certification program and the International Living Future Institute's Living Building Challenge focus on both occupants and the environment, whereas the WELL Building and Fitwel certification programs center on occupant health. Each of these certification programs provides roadmaps for decisionmaking during the evidence-based design process for healthy buildings. Table 2 outlines the 11 concepts in the WELL Building standard (22).

Today's concept of a healthy building is holistic: a structure intentionally designed, constructed, and operated so that it supports the health and safety of people and the planet. Many organizations have contributed to promoting

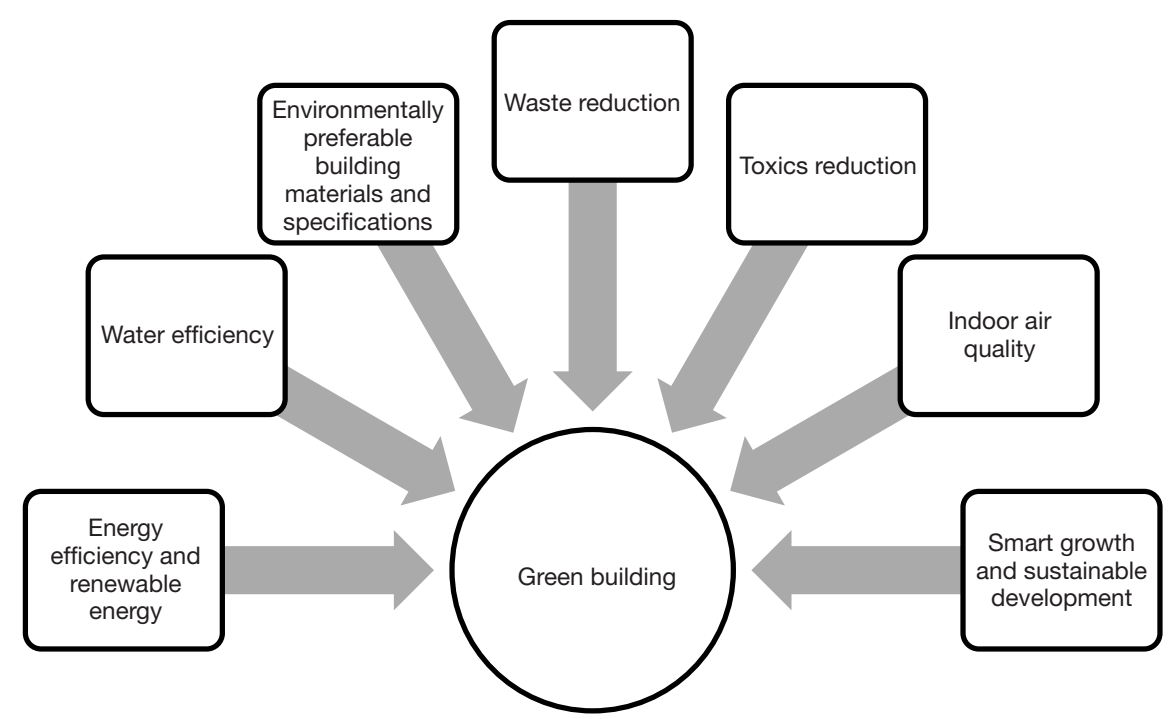

Figure 1 Green building components. Adapted from Ref. (18). 
Table 2 Eleven concepts in the WELL building standard

\begin{tabular}{|c|c|}
\hline No. & Concept \\
\hline 2. Water & $\begin{array}{l}\text { Increase rate of adequate hydration in building users, reduce health risks due to contaminated water and excessive } \\
\text { moisture, and provide adequate sanitation }\end{array}$ \\
\hline 3. Nourishment & Encourage healthy and sustainable eating patterns \\
\hline 5. Movement & $\begin{array}{l}\text { Encourage physical activity in everyday life by ensuring that movement opportunities are integrated into the fabric } \\
\text { of the culture, buildings, and communities }\end{array}$ \\
\hline 6. Thermal comfort & Improve human productivity and provide a maximum level of thermal comfort among all building users \\
\hline 7. Sound & $\begin{array}{l}\text { Bolster health and well-being by identifying and calibrating acoustical comfort parameters that shape the sound- } \\
\text { scape of the built environment }\end{array}$ \\
\hline 9. Mind & $\begin{array}{l}\text { Promote mental health through policies, programs, and design strategies to address the diverse factors that influ- } \\
\text { ence cognitive and emotional well-being }\end{array}$ \\
\hline 10. Community & $\begin{array}{l}\text { Support access to fundamental healthcare, build a culture of health that accommodates diverse population needs, } \\
\text { and establish an inclusive, engaged occupant community }\end{array}$ \\
\hline 11. Innovation & $\begin{array}{l}\text { Include other strategies to create healthier environments, such as green building certification and carbon disclosure/ } \\
\text { reduction }\end{array}$ \\
\hline
\end{tabular}

Adapted from Ref. (22).

healthy buildings in the U.S. and abroad (Table 3). These efforts typically integrate green building and well building design components, sustainable operating policies, and an evidence-based design process. Notably, the eight steps in the evidence-based design process include collecting baseline performance measures and measuring postoccupancy performance results-critical to documenting a return on investment necessary for making a "business case" encouraging greater attention to the healthy building movement.

By improving occupants' health and safety, healthy buildings also support the goals of the Joint Commission standards for improving the quality of healthcare and Planetree certification for person-centered care. Although these programs have no direct relationship with the healthy building certification programs, their intended outcomes are symbiotic.

\section{Transparency}

Alongside the evolution of sustainable design has come an emphasis on transparency in business. Meyer and Kirby proposed in a 2010 Harvard Business Review article that companies had long prospered by ignoring what economists call externalities- the various impacts that a business has on its broader milieu but is not obliged to pay for. Increasingly, however, many companies are adopting a different stance, thanks to growing industrial scale, better sensors, and heightened sensibilities. The best companies don't react defensively but apply their energies to mitigating the problems to which they contribute (23).

This demand for transparency has grown dramatically, and manufacturers of medical devices, building products and interior furnishings are revamping production to avoid harmful chemicals and examining their supply chains with an eye toward labor fairness, pollution effects, and other externalities. From understanding the carbon footprint of healthcare to the relationship between air pollution and health, "big data" is exponentially growing the evidence base for the relationship between the built environment and health at every scale-from the microscopic contents of products to the health effects on building occupants and surrounding communities. Both the demand for transparency and access to data are key drivers of accelerating interest in wellness by 
hospitals and health systems.

\section{Investing in healthy buildings}

Investments in healthy buildings reflect a commitment to the health, safety, and well-being of patients, staff, and the broader community. They can produce better patient outcomes, help frontline healthcare workers cope with job-related stress, and advance the business and strategic objectives of hospitals' and health systems' boards, shareholders, and investors. These investments embody corporate social responsibility and can support ESG (Environmental, Social, Governance) criteria.

\section{Health and safety for patients and staff}

Building design interventions-such as greater access to nature and natural daylight, improved air quality and acoustics, fewer chemicals in materials, and access to restorative spaces-can lower stress, promote better sleep, and improve respiratory function in patients and staff $(10,18,24)$. Patients who have access to positive visual and sensory stimuli, such as views of nature and artwork or access to quiet spaces, may require fewer pain medications and also sleep better $(25,26)$. Poor lighting, high noise levels, and inappropriate room temperature have been linked to increased medical errors among staff $(27,28)$. Job stress has also been linked to poor sleep quality among nurses (29), which may affect their performance. Nursing units that are spatially designed to get patients up and moving are associated with shorter hospital stays and improved fitness (30).

Building design features that promote mobility include wider corridors, visible and attractive stairways, and outdoor walking areas. The quality of air and water, access to handwashing facilities, level of humidity, availability of operable windows, and choice of surface materials for walls, floors, furniture, and countertops directly influence the risk for spread of infections (10). Selection of flooring materials (e.g., resilient vs. carpet) can help to reduce slips, trips, and falls-common occurrences (among hospital patients and staff) that affect recovery and often result in short- or longterm disability and/or chronic pain $(31,32)$. Durability and cleanability of surface materials may also impact safety and are important considerations for hospitals.

Menno Haven Rehabilitation Center in Chambersburg, Pennsylvania, is the first skilled nursing facility in the world to be WELL-certified at the gold level, which means that it achieved all of the WELL preconditions for the 10 main concepts (Table 2), as well as $40 \%$ or more of WELL's additional optimization features. LEED certification for the project was not pursued, and the WELL standards had to be adjusted to accommodate settings specific to rehabilitation, such as patient rooms and physical therapy spaces (33). To bring in natural light and allow views to the outdoors, each of the 44 patient rooms has a window with frosted glass above the eye level, as well as a tall, almost floor-to-ceiling window. These windows reduce the need for electric light and reinforce the natural patterns of the sun to support patients' circadian rhythms and sleep.

Administrator Deanna Beins shared in an interview for this article that Menno Haven's HVAC system, which has 96 air handlers and built-in ultraviolet-light treatments in common areas, easily exceeds OSHA's MERV (minimum efficiency reporting value) requirements for air filtration. The number of air handlers for a building this size $(47,000 \mathrm{sq}$. $\mathrm{ft}$.) is unusual and requires extra maintenance to change the filters, but Beins believes it is worth it. In a post-occupancy evaluation of the facility, patients with asthma reported positive effects of the indoor air quality and improved oxygen levels. Staff also indicated that the WELL standards, particularly the cleaning protocols and UV air-filtration systems, better prepared them to handle the COVID-19 pandemic and keep patients safe (33). Another unique feature of Menno Haven is its whole-building water filter, which had to be added when municipal water didn't meet WELL standards. According to Beins, patients routinely comment on the high quality of the water and good-tasting coffee. She also reports that surveys of patients have produced facility endorsement ratings at the $93 \mathrm{rd}$ percentile.

Design interventions can encourage healthful habits. Stairs can be made more visible and attractive for climbing, water stations and drinking fountains can be placed strategically to make patients more likely to pause for a drink, fruit and vegetables can be placed front and center in cafeterias, and vending machines with healthful food choices can be located in the highest-traffic areas. The aim is to reduce risk for chronic conditions such as obesity, diabetes, high blood pressure, headaches, and depression $(34,35)$.

When Lucile Packard Children's Hospital in Palo Alto, California, embarked on a major expansion in 2007, its senior leaders and board committed to aggressive sustainable design goals. The 521,000-square-foot LEED platinum-level certified building reduces energy demand by $60 \%$ below the regional average. Furthermore, carbon emissions have been cut by close to $90 \%$, due to Stanford 
University's central plant's efficiency and sourcing from Palo Alto Power, the first municipal utility in the U.S. to be fueled by $100 \%$ renewable energy (solar, wind, biomass); that's the equivalent of eliminating carbon from 16 million pounds of coal. Cisterns store rainwater, condensation, and dialysis-reject water to irrigate the extensive native and drought-tolerant landscaping, contributing to a $40 \%$ reduction in water use (36).

The new building also increased landscaped and open space by 3.5 acres. This space-including a vegetated roof and multiple outdoor gardens-harvests rainwater, helps to restore the natural environment, and increases biodiversity. Native or adapted plants require minimal irrigation, and when they do, only non-potable water from the cistern is used. Access to the outdoors, daylight, and views are prioritized; all stairways have windows; and a dedicated visitor stairway allows families to move among four patient floors, the available amenities, and the garden without using the elevator. On inpatient units, distinct dedicated terraces for families and staff allow quick access to the outdoors. During the pandemic the terraces were the only places for staff to remove their personal protective equipment while on the nursing units—an unanticipated co-benefit (36).

An emphasis on local materials connects the building to its community. The wood cladding on the elevator tower, for example, is old-growth redwood reclaimed from a nearby iconic dirigible hangar, deconstructed in 2015 . Locally produced ceramic tile covers the server walls. The building is themed around the particular ecoregions of the state of California, as opposed to generalized nature themes. Local material sourcing both reduces the carbon impacts associated with transportation and supports local economies, both of which improve community health and connect people to place. In addition, stunning interactive technology celebrates the Silicon Valley community.

The design team used architecture firm Perkins and Will's Precautionary List to screen out products and materials that contain potentially toxic substances. For example, the hospital has no PVC-containing building materials, and the furniture is free of flame-retardants and antimicrobials. The hospital also implemented greener cleaning protocols. The building performance and features are embedded in the patient and staff experience with visual-narrative displays that tell the story of energy and water use and locally sourced materials (people interested in learning more can use their phones to scan QR codes within the displays). In a variety of ways, the building anchors the hospital's sustainable operations initiatives.

\section{Staff satisfaction and productivity}

The aforementioned interventions also contribute to staff satisfaction, well-being, and productivity, which can reduce turnover and absenteeism, potentially saving huge sums each year $(37,38)$. Poor design increases the incidence of staff injuries from falling (uneven flooring surfaces), lifting patients (lack of patient lifts), or excessive walking/standing (distant equipment storage). Staff in poor physical or mental health may still come to work, but their productivity suffers (a phenomenon called "presenteeism"). Research indicates that presenteeism among employees is far costlier than illness-related absenteeism or disability (39-41).

In November 2012, Adelante Healthcare opened the first LEED platinum-certified community health center in the U.S. in Mesa, Arizona. Using an evidence-based design process, the team incorporated many features of healthy buildings to promote energy efficiency, reduce carbon footprint, and increase staff satisfaction and productivity. The features included access to natural daylight, LED lighting, positive distractions such as a variety of color and art, staff respite rooms, a staff lounge with access to a patio, an outdoor walking path, and a café emphasizing healthier foods. Within the first year of operation, administrators at the new facility reported a $46 \%$ reduction in absenteeism, declining turnover rates, and reduced staff stress. Overall staff satisfaction with the new facility and with the workplace in general was high. For example, $82 \%$ felt that the building's daylighting had a positive effect on their ability to do their job (perceived productivity), compared with only $33 \%$ in a similar, non-LEED Adelante facility. Energy use also declined by $20 \%$, and water consumption fell by $70 \%$ (42). In addition, Adelante notes that their building certification has impacted their community in qualitative ways as well: through expanded mutually beneficial partnerships, additional patient resources, and expanded influence (43).

\section{Community outcomes}

Hospitals and health systems serve a unique community of people with diverse characteristics who engage in joint action and experiences in shared settings or locations (44). Hospital pollution impacts the community and society at large. Gary Cohen, CEO of Health Care Without Harm, writes of U.S. health systems, "Globally, if the health sector were a country, it would be the fifth-largest emitter of greenhouse gasses." (45). The 2015 landmark Lancet Commission on Climate and 
Table 3 Milestones in green design, sustainable healthcare practices, and WELL building design movements in the U.S.

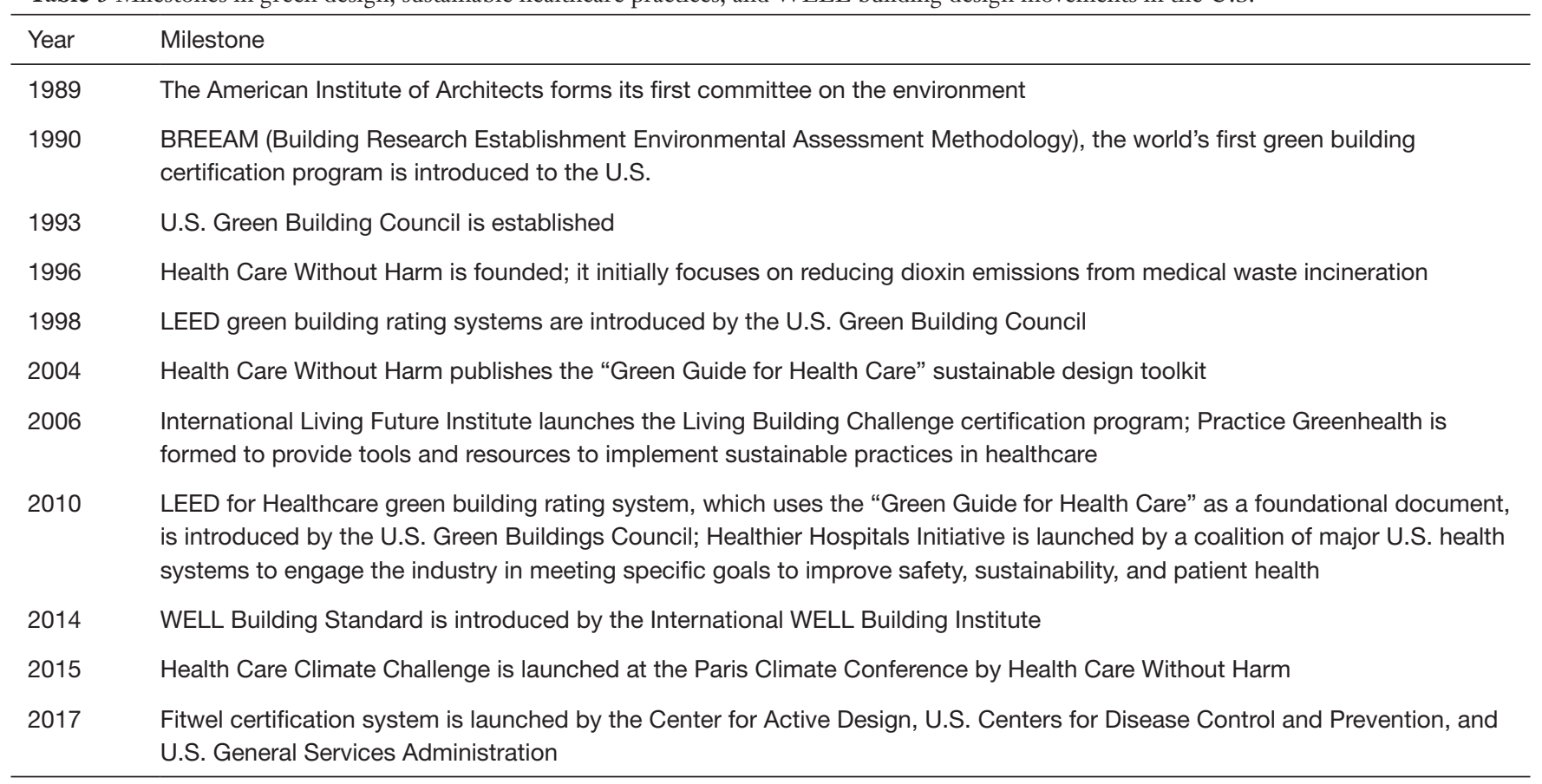

Health (46) noted that climate change effects "represent an unacceptably high and potentially catastrophic risk to human health" with the potential to undo more than 50 years of global public health gains. In its updated 2020 report (47), the Commission noted: "The changing climate has already produced considerable shifts in the underlying social and environmental determinants of health at a global scale." During the past 20 years, the authors note, heat-related deaths among people older than 65 have increased by $53.7 \%$ (43).

Air pollution, particularly related to fossil fuel emissions, is responsible for 9 million premature deaths annually, more than $16 \%$ of all premature deaths globally (48). The publication of original academic research on health and climate change has increased eightfold from 2007 to 2019 (43). The 2020 Lancet report notes: “... some of the most considerable progress was seen in the growing momentum of the health profession's engagement with climate change globally." (47). Taken together, this science is underpinning a range of carbon reduction and healthy building initiatives in health systems across the United States.

NYU Langone Health's Manhattan main campus is the first in the world to achieve both USGBC's LEED Platinum and Performance Excellence in Electricity Renewal (PEER) standards certification. A pair of co-generation plants powers the coastline campus, which features extensive flood-protection infrastructure and a 12,000-square-foot green roof to more effectively manage peaks in storm water accumulation. Since prioritizing sustainability, NYU Langone has reduced greenhouse gas emissions by $37 \%$, and it participates in the Healthier Hospitals Safer Chemical Challenge, whereby more than $30 \%$ of its annual volume of medical furniture purchases have become free of chemicals of concern. NYU Langone's Green First program includes healthier and local food, electric vehicle fleets, water conservation, and waste reduction. It also uses both the Fitwel and WELL certification programs to guide major interior renovations (49).

One of the opportunities that NYU Langone has realized is an increase in outdoor green space, a difficult challenge in densely populated Manhattan. Its green roof and extensive landscaping offer healing outdoor spaces for patients, staff, and visitors, as well as habitat for birds and pollinators.

Building and community design play critical roles in addressing the social and physical determinants of health. Providing access to nature, reducing exposure to toxic substances, and making buildings accessible and safe are some of the ways to create social and physical environments that promote good health for all (50). Spaces that are truly inclusive comply with accessibility codes and incorporate the seven universal design principles (Table 4), which enable people of all needs, abilities, and identities to use them $(51,52)$. 
Table 4 Seven principles of universal design

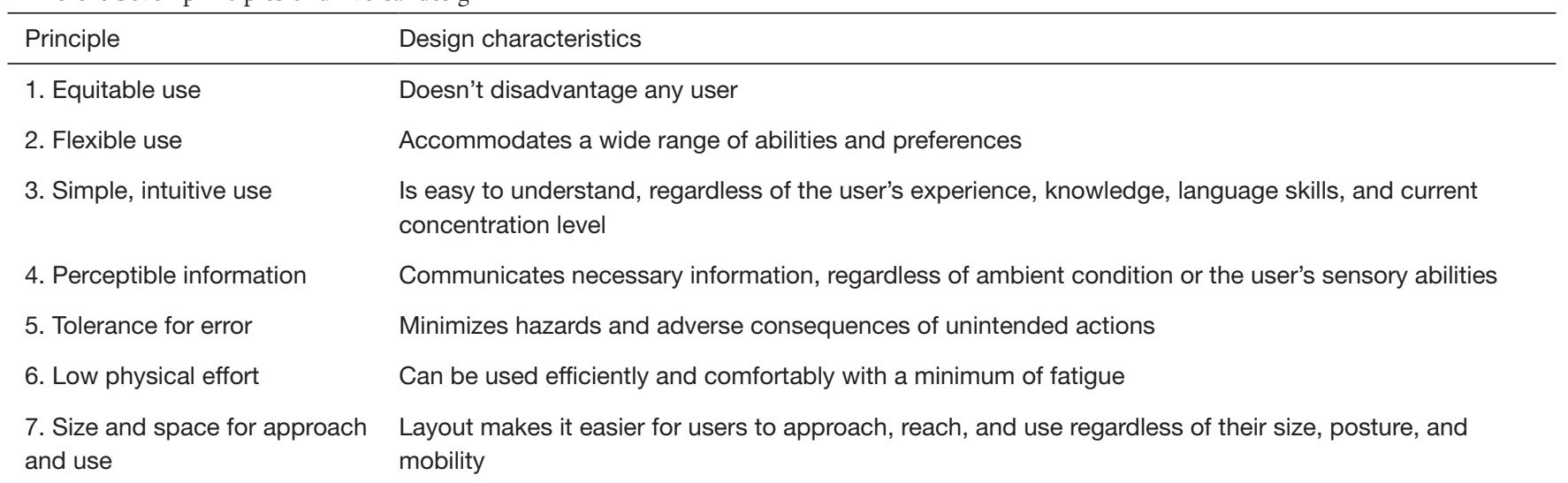

Adapted from Ref. (51).

Healthy buildings are a means of prioritizing population health. For example, in Fayetteville, Georgia, Piedmont Health System opened a 55,000-square-foot wellness center in 2019. Located within a residential community, the center emphasizes holistic physical and mental health. Test kitchens promote nutrition, and classrooms teach meditation. A giant slide, parallel to a main stairway, adds an element of fun and joy. Boot-camp-style workout areas with floor-to-ceiling doors open during favorable weather. Hiking trails run through a grove of trees just beyond the building's footprint. Walkers can find art installations along the way. Designed to push the forefront of preventive medicine facilities, Piedmont combines a state-of-theart fitness and sports training facility (including a pool) with access to nutritional counseling and outpatient rehabilitation services.

Piedmont's wellness center prioritizes access to nature and the use of heavy timber, which has a much lower carbon footprint than steel and connects occupants to nature while indoors. The Atlanta fournal-Constitution called the facility "a bridge between medical care and wellness" (53). According to Michael Burnett, CEO of Piedmont Healthcare: "This (is) the first time that Piedmont has integrated a bealth and wellness location within a residential community. We believe this innovative facility will not only be a gold standard fitness facility for people of all ages and abilities but will also be the best way to deliver preventive medicine and healthcare solutions for a community focused on wellness and living better." (54).

\section{Payer, shareholder, and investor outcomes}

The return on investment of a healthy building can be substantial. Using hard data from hospitals, Sadler et al. (9) analyzed and estimated the influence of evidence-based design interventions in a new hospital building on outcomes and operating costs. Improved outcomes included reduced rates of patient falls, transfers, adverse drug effects, and healthcare-associated infections-and shorter lengths of stay. Also considered were reductions in nurse turnover and injuries, as well as reduced energy and water demand. Overall, the authors calculated annual savings_-of just over $\$ 10$ million - that would make up for the additional investment within three years. These savings would continue long after paying off the added costs of prioritizing healthy building design. Moreover, the authors did not include in their calculations any estimates of increased revenue that might occur when an appealing facility attracts more patients as customers and clinicians as employees.

In addition, sustainability measures, such as reduced carbon emissions and energy consumption that are crucial to the health of people and the planet can result in operational savings (11). A healthy building also enhances the patient experience, which may produce better HCAHPS scores and reduce Medicare penalties (55).

With committed leadership, technical expertise, and ingenuity, health systems can dramatically reduce their environmental impacts and save money. Consider the example set by Gundersen Health Systems in La Crosse, Wisconsin. After initiating its "Envision" environmental program in 2008, Gundersen became the first U.S. healthcare organization to offset $100 \%$ of its fossil-fuel use with self-produced energy. Gundersen not only benefits the community environmentally but also saves more than $\$ 3$ million annually through energy conservation, waste 
management, recycling, and sustainable facility design. It also works with local lumber mills to purchase waste wood chips that it uses in a biomass boiler to produce electricity and steam, thereby leveraging its fuel-purchasing dollars to support the local economy. Gundersen formed a partnership with the Onalaska Department of Public Works to harvest landfill methane (a potent greenhouse gas) for electricity and heat; it now also harvests dairy manure, which had previously formed toxic runoff in Wisconsin lakes. Envision was inspired by Jeff Thompson, Gundersen's CEO at the time, who stated in an interview for this article that his most important decision was framing the purpose of the organization to serve the greater good of physical, emotional, psychological and environmental health: "We are an externally facing organization; we are not just a 'fix-it' shop." Thompson said.

The concept of a healthy building also aligns with many of the Environmental, Social, and Governance (ESG) policies set by health system leaders and board members. This alignment becomes even more important as investors start to make strong ESG polices part of their lending requirements. Research has also shown that companies with a strong ESG agenda are more likely to perform well financially (56).

As organizations are increasingly reporting on ESG, investments in healthy buildings are part of their materiality assessment. Using third-party systems to verify a comprehensive approach to healthy buildings elevates the validity and trackability of the assets and impact on employees over time. For example, companies whose employees report high scores on health and wellbeing consistently outperform the Standard \& Poor's 500 index (57). In addition, federal bipartisan legislation introduced in 2021 would create tax credits for employers that create healthy workplaces (58).

\section{Taking concrete action}

Hospitals and health systems that are not already on the path to creating buildings and interior environments that support the health and well-being of people and the planet can take several concrete steps to begin the process.

\section{Articulate a shared vision and common goals}

The first big step is to make a formal commitment to the effort, reinforced by educating administrative and clinical leadership about the ongoing patient, staff, financial, and community benefits of designing a healthy healthcare building. Health system leaders should consider engaging an external knowledge expert as well as internal champions to help articulate the vision. If possible, focus on local environmental issues that staff and patients experience in their daily lives—and look for opportunities to partner with local organizations. It's essential to get buy-in from all levels of leadership and all major stakeholders-and to cultivate a clear understanding of the resources and time needed to achieve success. Everyone involved must develop a shared understanding of the relationship between the built environment and health, and the evidence that supports it.

This high-level collaborative process requires the steady hand of a champion whose vision and leadership skills are well established in the organization. For example, Gundersen Health System's CEO Jeff Thompson, named a "Champion of Change" by the Obama White House in 2013, stressed the importance of ongoing and consistent communications to all levels of the organization, including clinicians who might be worrying-as Thompson put it in his interview for this article- "What are we doing? Are you going to take windmills versus my scopes for the GI lab or a new operating room?" Thompson explains: "One of the advantages I had as a CEO is that I had this rhythm of going out and speaking to staff on a regular basis. I told them that I took our environmental commitment to the board to lower the cost of care, improve our local economy and stop polluting so much, which harms our patients. I used the same message over and over, adding stories and data to back it up."

\section{Appoint a task force}

A task force to oversee healthy building initiatives should consist of people who represent various interests, such as clinical care, environmental services, design and construction, facility management, supply chain, patient experience, community relations, IT, marketing, and human resources-and who have the requisite expertise and commitment to the cause. Besides creating a strategic plan and budget for achieving healthy buildings, the task force can participate in developing a long-term master plan and designing standards for new projects and renovations. For instance, Seattle Children's Hospital published a "Green Building Design Commitment" in 2016 to guide future development (59). Beginning with development principles, the guide provides a roadmap for design teams to use in all projects. Task forces also can take the lead in evaluating the site selection process and the environmental footprint of the 
organization's real estate portfolio.

It also can be important for a task force to contribute to educating others in the organization about how healthy buildings align with their own core values and purpose and, specifically, to establish organization-wide long-term goals. Publicly stated goals engage the broader community in achieving better population health. Kaiser Permanente, for example, published its "2025 Environmental Stewardship Goals" (60) and achieved its "carbon net positive" goal 5 years earlier than anticipated (61).

\section{Cultivate communication}

Once the program is underway, empower marketing teams and give them the resources to create messaging and tools. These tools can then be used both internally and externally to communicate why the decision was made to create healthy buildings-and the desired concrete benefits. Consider creating a community campaign to foster awareness through local TV and newspaper advertising, billboards, social media, town hall meetings, and other means. Encourage staff to share updates with their social media followers. Focus the messaging on why this is being done rather than merely how it's being implemented.

Kaiser Permanente, for example, anchors its environmental stewardship/healthy building programs in its community benefit work, under the umbrella of "Total Health". Kaiser has a website dedicated to its goals, and engaged clinical leaders speak publicly about the urgency of addressing climate and health in both its buildings and broader supply chain (60).

\section{Foin forces}

Seek mutually beneficial partnerships with interested organizations in the community that can bring expertise and other resources to amplify the benefits of healthy buildings and accelerate their practicality. Gundersen Health's Envision, for example, partners with various community organizations to implement its renewable energy projects, such as partnering with the Onalaska Department of Public Works to transform waste biogas from a landfill into electricity and heat for one of its campuses. Boston Medical Center (BMC), an urban safety net hospital, partnered with Massachusetts Institute of Technology and the Post Office Square Redevelopment Corporation to invest in a North Carolina solar farm and shift $100 \%$ of BMC's electricity demand to renewable power (62).

Cleveland Clinic and other area hospitals are members of the Cleveland Tree Coalition, a nonprofit program focused on using reforestation to restore Cleveland to the "garden city" it once was (63). Since the 1960s, Cleveland has lost close to $50 \%$ of its trees. Cleveland Clinic notes that implementing climate resilience measures, like the 4,000 trees it has planted since 2016, has direct community health benefits: "We communicate the interconnectedness of environmental and human bealth to our stakebolders." (64).

\section{Leverage the standards}

Authorize and provide the resources for key staff members from design and construction and/or facility management to become WELL- and LEED-accredited. Also require consultants on building planning, design, and construction teams to be WELL- and LEED-accredited and to use an evidence-based design process to make decisions. Develop design standards that prioritize healthy building strategies, such as enhanced indoor air quality, minimizing toxic chemicals, and certification of projects through LEED, WELL, and Fitwel.

Integrate the healthy building concept into requests for proposals (RFP) on new and renovation construction projects. Clearly stating goals and requirements in the RFP is the best way to ensure that project teams are engaged from the start and can seamlessly integrate the requirements into the design process. For instance, NYU Langone requires LEED Gold certification on major new construction and renovation, while all of its projects consider WELL, Fitwel, and International Institute for Sustainable Laboratories (I2SL) standards on a caseby-case basis. NYU Langone also uses the Practice Greenhealth Healthy Interiors Challenge to purchase furnishings free of chemicals of concern, including antimicrobial treatments (65).

\section{Measure and recalibrate progress}

It's also important to fund data collection efforts. Engage researchers who study built environments to work with the planning, design, and construction teams at the start of each project. Together these groups should develop hypotheses, collect baseline performance measures, and gauge postoccupancy performance results. Building performance data on energy and water use are easily tracked by analyzing operating costs before and after completion of new projects. 
Other impacts can be measured by empirical studies like one conducted by Harvard University: Sampling indoor dust in 47 rooms from 21 buildings, the researchers found that dust in rooms with furniture that met the Practice Greenhealth Healthy Interiors challenge had far fewer chemicals of concern than dust in rooms with furniture that did not meet this Greenhealth standard (66).

To measure staff satisfaction and perceived productivity in its new Mesa facility, Adelante Healthcare used data from an online employee engagement survey it conducts every year. It also engaged the Center for the Built Environment at the University of California Berkeley to develop a survey to measure staff satisfaction related to the facility. Adelante Healthcare also surveyed staff stress levels using the Nursing Stress Scale, developed by researchers at Methodist Hospital of Indiana and Purdue University $(43,67)$.

\section{Conclusions}

Healthcare institutions can and should be catalysts for defining and advancing community and population health. Today, however, the influence of the healthcare sectorwith notable exceptions-is largely confined to specific disease-management activities for individual patients, rather than having a holistic mission within a broader health ecosystem.

Americans have long accepted that our built environments, including our healthcare buildings, inevitably have a set of negative unintended consequences—sedentary lifestyles, greenhouse gas emissions, chemical exposures, among other externalities. But there's actually no reason for healthcare buildings to add to the barriers people face in becoming and staying healthy. Indeed, as we have shown, using an evidence-based design process along with green and well standards to create built environments can make it easier, not harder, to improve individual and population health —and, in the process, foster joy and satisfaction for patients and healthcare staff.

We hope that the "healthy building" priorities we have outlined-along with our examples of institutions that are successfully implementing these priorities-will inspire a broader range of healthcare organizations to follow suit, tailoring their efforts to the needs and constraints of their own patients and communities. It is only by taking concrete actions, similar to those we recommend, that health system leaders will make it possible for their built environments to promote, rather than impede, improvements in human health and planetary survival.

\section{Acknowledgments}

The authors thank Deanna Beins, Menno Haven Rehabilitation Center; Audrey Bohanan, Adelante Healthcare; and Jeff Thompson, Gundersen Health System for agreeing to be interviewed for this article. The authors also acknowledge The Center for Health Design, Health Care Without Harm, the International WELL Bulding Institute, and the U.S. Green Building Council for their tireless advocacy of creating buildings that do not harm people or planet.

Funding: None.

\section{Footnote}

Provenance and Peer Review: This article was commissioned by the Guest Editors (Stephen J. O'Connor, Nancy Borkowski and Katherine A. Meese) for the series "Shaping Tomorrow's Healthcare Systems: Key Stakeholders' Expectations and Experiences" published in Fournal of Hospital Management and Health Policy. The article has undergone external peer review.

Conflicts of Interest: All authors have completed the ICMJE uniform disclosure form (available at https://jhmhp.amegroups. com/article/view/10.21037/jhmhp-21-63/coif). The series "Shaping Tomorrow's Healthcare Systems: Key Stakeholders' Expectations and Experiences" was commissioned by the editorial office without any funding or sponsorship. The authors have no other conflicts of interest to declare.

Ethical Statement: The authors are accountable for all aspects of the work in ensuring that questions related to the accuracy or integrity of any part of the work are appropriately investigated and resolved.

Open Access Statement: This is an Open Access article distributed in accordance with the Creative Commons Attribution-NonCommercial-NoDerivs 4.0 International License (CC BY-NC-ND 4.0), which permits the noncommercial replication and distribution of the article with the strict proviso that no changes or edits are made and the original work is properly cited (including links to both the formal publication through the relevant DOI and the license). See: https://creativecommons.org/licenses/by-nc-nd/4.0/.

\section{References}

1. Dovjak M, Kukec A. Health outcomes related to built 
environments. In: creating healthy and sustainable buildings. Cham (CH): Springer, 2019:43-82.

2. Bakhamis L, Paul DP 3rd, Smith H, et al. Still an Epidemic: The Burnout Syndrome in Hospital Registered Nurses. Health Care Manag (Frederick) 2019;38:3-10.

3. Johnson SR. Healthcare should link social determinants with environmental sustainability. Available online: https:// www.modernhealthcare.com/safety-quality/healthcareshould-link-social-determinants-environmentalsustainability

4. Eckelman MJ, Huang K, Lagasse R, et al. Health Care Pollution And Public Health Damage In The United States: An Update. Health Aff (Millwood) 2020;39:2071-9.

5. Christopoulou-Aletra H, Togia A, Varlami, C. The "smart" asclepieion: A total healing environment. Arch Hellen Med 2010;27:259-63.

6. Nightingale, F. Notes on hospitals. London: Longman, Green, Longman, Roberts, and Green, 1858.

7. Gonzalo A. Florence Nightingale: Environmental theory. Nurseslabs. Mar 5, 2021. Available online: https:// nurseslabs.com/florence-nightingales-environmentaltheory. Accessed June 2021.

8. Center For Health Design. An Introduction to EvidenceBased Design: Exploring Healthcare and Design. Third edition. Concord, USA: The Center for Health Design, Inc., 2015.

9. Sadler BL, Berry LL, Guenther R, et al. Fable hospital 2.0: the business case for building better health care facilities. Hastings Cent Rep 2011;41:13-23.

10. Ulrich RS, Zimring C, Zhu X, et al. A review of the research literature on evidence-based healthcare design. HERD 2008;1:61-125.

11. Guenther R, Vittori G. Sustainable Healthcare Architecture. 2nd Edition. Hoboken, NJ: John Wiley \& Sons, 2013.

12. Malkin J. A visual reference for evidence-based design. Concord, USA: The Center for Health Design, 2008.

13. Marberry S. Improving healthcare with better building design. Chicago, IL: Health Administration Press, 2006.

14. Facilities Guidelines Institute. The knowledge repository. The Center for Health Design. 2019. Available online: https://www.fgiguidelines.org/wp-content/ uploads/2019/02/CHD_Knowledge_Repository_FGI.pdf

15. Butler CD. Climate Change, Health and Existential Risks to Civilization: A Comprehensive Review (1989-2013). Int J Environ Res Public Health 2018;15:2266.

16. Mirsaeidi M, Motahari H, Taghizadeh Khamesi M, et al. Climate Change and Respiratory Infections. Ann Am
Thorac Soc 2016;13:1223-30.

17. Passarelli G. Sick building syndrome: An overview to raise awareness. J Build Apprais 2009;5:55-66.

18. Environmental Protection Agency Web Archive. Green building: components of green building. Available online: https://archive.epa.gov/greenbuilding/web/html/ components.html

19. Wilson EO Biophilia. MA, USA: Harvard University Press, 1984.

20. Kellert SR, Heerwagen JH, Mador M. Biophilic Design: the Theory Theiry, Science, and Practice of Bringing Buildings to Life. NJ, USA: Wiley, 2008.

21. Ryan CO, Browning WD, Clancy JO, et al. Biophilic Design Patterns: Emerging Nature-Based Parameters for Health and Well-Being in the Built Environment. Archnet-IJAR 2014;8:62-76.

22. International WELL Building Institute. WELLv2 overview and features. Available online: https:// v2.wellcertified.com/wellv2/en/overview

23. Meyer C, Kirby J. Leadership in the age of transparency. Harv Bus Rev 2010;88:38-46.

24. Rossi M, Lent T. Creating safe and healthy spaces: selecting materials that support healing. The Center for Health Design. 2006. Available online: https://www. healthdesign.org/knowledge-repository/creating-safe-andhealthy-spaces-selecting-materials-support-healing

25. Malenbaum S, Keefe FJ, Williams ACC, et al. Pain in its environmental context: implications for designing environments to enhance pain control. Pain 2008;134:241-4.

26. BaHammam A. Sleep in acute care units. Sleep Breath 2006;10:6-15.

27. Leather P, Beale D, Sullivan L. Noise, psychosocial stress and their interaction in the workplace. J Environ Psychol 2003;23:213-22.

28. Kaboodmehri R, Hasavari F, Adib M, et al. Environmental factors contributing to medication errors in intensive care units. J Holist Nurs Midwifery 2019;29:57-64.

29. Deng X, Liu X, Fang R. Evaluation of the correlation between job stress and sleep quality in community nurses. Medicine (Baltimore) 2020;99:e18822.

30. National Institute for Health Research. Getting hospital patients up and moving shortens stay and improves fitness. April 16, 2019. Available online: https://evidence.nihr. ac.uk/alert/getting-hospital-patients-up-and-movingshortens-stay-and-improves-fitness/

31. Nanda U, Malone EB, Joseph A. Achieving EBD goals through flooring selection and design. Concord, USA: 
The Center for Health Design, 2012.

32. J+J Flooring Group. Flooring selection for acute care facilities: safety implications. 2014. Available online: https://docplayer.net/2412672-Flooring-selection-foracute-care-facilities-safety-implications.html

33. SAGE (Society for the Advancement of Gerontological Environments). Menno Haven Rehabilitation Center: post-occupancy evaluation to explore what works. 2020. Available online: https://sagefederation.org/initiatives/ post-occupancy-evaluations/

34. Cedeño-Laurent JG, Williams A, MacNaughton P, et al. Building Evidence for Health: Green Buildings, Current Science, and Future Challenges. Annu Rev Public Health 2018;39:291-308.

35. Healthline. 2021. 7 science-based health benefits of drinking enough water. Available online: https://www. healthline.com/nutrition/7-health-benefits-of-water

36. U.S. Green Buildings Council. Lucile Packard Children's Hospital Stanford. Available online: https://www.usgbc. org/resources/case-study-lucile-packard-childrenshospital-stanford

37. CDC Foundation. 2015. Worker illness and injury costs U.S. employers $\$ 225.8$ billion annually. Jan 28. Available online: https://www.cdcfoundation.org/pr/2015/workerillness-and-injury-costs-us-employers-225-billionannually

38. Guenther R, Hall AG. Healthy buildings: impact on nurses and nursing practice. Online J Issues Nurs 2007;12:2.

39. Palacios J, Eichholtz P, Kok N. Moving to productivity: The benefits of healthy buildings. PLoS One 2020;15:e0236029.

40. Hemp P. Presenteeism: at work--but out of it. Harv Bus Rev 2004;82:49-58, 155.

41. Homrich PHP, Dantas-Filho FF, Martins LL, et al. Presenteeism among health care workers: literature review. Rev Bras Med Trab 2020;18:97-102.

42. Center for Health Design. Adelente Healthcare. 2021. Available online: https://www.healthdesign.org/researchservices/pebble-project/partners/adelante-healthcare

43. Taylor E, Wingler D. Community Health Center Asks: To LEED or Not To LEED? Healthcare Design, December 31, 2013. Available online: https:// healthcaredesignmagazine.com/trends/architecture/ community-health-center-asks-leed-or-not-leed/

44. MacQueen KM, McLellan E, Metzger DS, et al. What is community? An evidence-based definition for participatory public health. Am J Public Health 2001;91:1929-38.

45. Cohen G. Climate change calls for a new Hippocratic oath. Health Aff Blog 2021. Available online: https://www. healthaffairs.org/do/10.1377/hblog20210712.613867/full/

46. Watts N, Adger WN, Agnolucci P, et al. Health and climate change: policy responses to protect public health. Lancet 2015;386:1861-914.

47. Watts N, Amann M, Arnell N, et al. The 2020 report of The Lancet Countdown on health and climate change: responding to converging crises. Lancet 2021;397:129-70.

48. Landrigan PJ, Fuller R, Acosta NJR, et al. The Lancet Commission on pollution and health. 2017. Available online: http://www.thelancet.com/commissions/pollutionand-health

49. Shinn K, Guenther R. Growing green rating systems in healthcare design. Healthcare Design. 2021. Available online: https://healthcaredesignmagazine.com/trends/ growing-green/

50. U.S. Department of Health and Human Services. Healthy People 2030: Social Determinants of Health. Available online: https://www.healthypeople.gov/2020/topicsobjectives/topic/social-determinants-of-health

51. Story MF. The principals of Universal Design. In: Universal Design Handbook. Second Edition. Preiser W, Smith KH, eds. New York: McGraw Hill, 2011.

52. Persson H, Åhman H, Yngling AA, et al. Universal design, inclusive design, accessible design, design for all: different concepts-one goal? On the concept of accessibilityhistorical, methodological and philosophical aspects. Univers Access Inf Soc 2015;14:505-26.

53. Stafford L. Officials break ground on Fayetteville Wellness Center near Pinewood Studios. Atlanta JournalConstitution. 2018. Available online: https://www.ajc. com/news/local-govt--politics/officials-break-groundfayetteville-wellness-center-near-pinewood-studios/ kSIMPtMJrCoD9TBC4eM40H/

54. Perkins and Will. Piedmont Wellness Center: an exercise in health. Available online: https://perkinswill.com/project/ piedmont-wellness-center/

55. Golbazi M, Aktas CB. LEED certification and patient wellbeing in green healthcare facilities. Journal of Green Building 2020;15:3-18. Available online: doi: 10.3992/ jgb.15.4.3

56. Bank of America. A healthcare-specific framework for ESG principles. Health Leaders Media. 2019. Available online: https://www.bofaml.com/en-us/content/healthcare-esgpriorities.html

57. Fabius R, Phares S. Companies That Promote a Culture of Health, Safety, and Wellbeing Outperform in the Marketplace. J Occup Environ Med 2021;63:456-61. 
58. Hartke J. To build back better, invest in people-first places. GRESB. 2021 Available online: https://gresb.com/tobuild-back-better-invest-in-people-first-places/

59. Practice Greenhealth. Seattle children's green building design commitment. 2021. Available online: https:// practicegreenhealth.org/tools-and-resources/seattlechildrens-green-building-design-commitment-2016

60. Kaiser Permanente. Kaiser Permanente's 2025 environmental stewardship goals: raising the bar on environmental responsibility. 2021. Available online: https://about.kaiserpermanente.org/content/dam/internet/ kp/comms/import/uploads/2016/05/EnvStewGoals2025_ FINAL2.pdf

61. Kaiser Permanente. The first carbon neutral health system in the U.S. Press Release, September 14, 2020. Available online: https://about.kaiserpermanente.org/communityhealth/news/first-carbon-neutral-health-system-in-us

62. Boston Medical Center. Embracing the sun: BMC moves closer to a carbon-neutral campus with a unique solar partnership. 2021. Available online: https://www.bmc.org/

doi: $10.21037 /$ jhmhp-21-63

Cite this article as: Marberry SO, Guenther R, Berry LL. Advancing human health, safety, and well-being with healthy buildings. J Hosp Manag Health Policy 2022;6:18. about-us/environmentally-friendly-campus/solar

63. Sustainable Cleveland. Cleveland tree coalition. 2021. Available online: https://www.sustainablecleveland.org/ cleveland_tree_coalition

64. Cleveland Clinic. Community tree planting. 2021. Available online: https://my.clevelandclinic.org/about/ community/sustainability/sustainability-global-citizenship/ environment/climate-resilience\#community-treeplanting-tab

65. Agins J. The future of healthcare green building rating and certification systems. New Orleans, LA: Session D02 Presentation at Healthcare Design, 2019.

66. Young AS, Hauser R, James-Todd TM, et al. Impact of "healthier" materials interventions on dust concentrations of per- and polyfluoroalkyl substances, polybrominated diphenyl ethers, and organophosphate esters. Environ Int 2021;150:106151.

67. Gray-Toft P, Anderson JG. The nursing stress scale: development of an instrument. J Behav Assess 1981;3:11-23. 